\title{
Contribuição de um periódico para o avanço científico acadêmico na Amazônia: visão e perspectivas dos editores da Revista de Administração e Negócios na Amazônia
}

\author{
THEOPHILO ALVES de SOUZA FiLho' \\ MARILUCE PAES-DE-SOUZA ${ }^{1}$ \\ DÉRCIO BERNARDES DE SOUZA²
}

\author{
1 Universidade Federal de Rondônia (UNIR) / Programa de Pós-GraduaçÃo em Administração, Porto VelHo - RO, Brasil

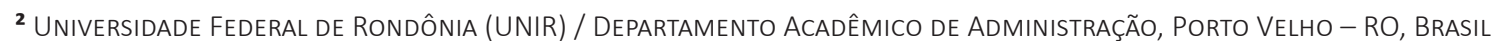

\begin{abstract}
Resumo
Este artigo relata a experiência dos editores de uma revista de Administração e Negócios na Amazônia, considerando a contribuição desse periódico para o avanço científico acadêmico com foco no desenvolvimento sustentável. O objeto do estudo é a Revista de Administração e Negócios na Amazônia (Rara). A Rara foi criada por pesquisadores do Centro de Estudo Interdisciplinar em Desenvolvimento Sustentável da Amazônia (Cedsa), cujo grupo de pesquisa é vinculado ao Programa de Pós-Graduação em Administração da Universidade Federal de Rondônia (PPGA/Unir). O estudo tem abordagem qualitativa, de natureza exploratória, com o objetivo de descrever a trajetória da revista. Os procedimentos foram orientados a relatar a experiência de seus editores. Utilizou-se como base de dados o site da própria revista. Os dados transformados em informações serviram de base para analisar a contribuição do periódico para o avanço científico acadêmico na Amazônia. Descrevem-se as estratégias de criação, editoração, penetração no âmbito acadêmico e avanço da Rara, pontuando a visão e as perspectivas de seus editores. Avaliamos que a iniciativa é pertinente e vem contribuindo com o desenvolvimento da Amazônia, no entanto, ainda se ressente de maior participação na produção científica de autores residentes nos estados da região Norte, bem como do baixo nível de qualidade nos trabalhos submetidos. Concluímos que o esforço de editoração para manter um periódico quadrimestral retrata a satisfação dos editores em contribuir com a disseminação do conhecimento e oferecer aos pesquisadores e acadêmicos da Amazônia e da comunidade científica como um todo um veículo para compartilhar suas reflexões e resultados de pesquisa sobre a Região.
\end{abstract}

Palavras-chave: Periódico. Avanço Científico Acadêmico. Amazônia.

Journal Contribution to the Scientific and Academic Advancement of the Amazon: visions and perspectives from the editors of Revista de Administração e Negócios na Amazônia

\section{Abstract}

This article aims to report the experience of the editors of a journal dedicated to the study of administration and business in the Brazilian Amazon. The article will discuss the contribution of the journal Revista de Administração e Negóciosna Amazônia (Rara) to the advancement of science and academia while focusing on sustainable development. Rara was created by researchers at the Center for Interdisciplinary Studies in Sustainable Development of the Amazon (Cedsa), whose research group is part of the Pos-Graduation Program in Administration of the Universidade Federal de Rondônia, in Rondônia, Brazil. The study uses a qualitative approach, exploratory in nature, with the objective of reporting the experience of the Journal. The research procedure reports the experience of its editors. The Journal website, papers and editorials were used as data. The data became information that served as the basis to analyze the contributions of the journal to the advancement of science and academia in the Amazon. We describe the strategies for creation, editing and penetration in the academic world and the progress of Rara, punctuating the vision and perspective of its editors. We assess that the initiative is pertinent and has been contributing to the development of the Amazon region, however, it is still resented by the greater participation of authors from the North Region, as well as the low quality of paper submissions. It is concluded that the efforts of editing to keep a tri-annual journal portrays the satisfaction of the editors in contributing to the dissemination of knowledge and making available to researchers and academics of the Amazon region a vehicle in which they can share its reflections and researchresults within the local region and all the scientific community.

Keywords: Journals. Academic-Scientific Advancement. Amazon.

Contribución del periódico al progreso académico-científico en la Amazonia: visión y perspectivas de los editores de la Revista de Administração e Negocios da Amazônia

\section{Resumen}

Este artículo tiene como objetivo relatar la experiencia de los editores de una revista de administración y negocios en la Amazonía, considerando la contribución de ese periódico al avance académico-científico y enfocando el desarrollo sustentable. La revista objeto del estudio es la Revista de Administração Negócios da Amazônia (Rara). La Rara fue creada por estudiosos del Centro de Estudio Interdisciplinario en Desarrollo Sustentable de la Amazonía (Cedsa) - un grupo de investigación vinculado al Programa de Postgrado en Administración de la Universidad Federal de Rondônia (RO). El estudio tiene un enfoque cualitativo, de naturaleza exploratoria, con el objetivo de describir la trayectoria de la revista. Los procedimientos se han orientado a relatar la experiencia de sus editores. La base de datos fue el sitio web de la propia revista. Los datos, transformados en información, sirvieron de base para analizar la contribución del periódico al avance académico-científico en la Amazonia. Se describen las estrategias de creación, publicación, penetración en el ámbito académico y avance del periódico Rara, señalando la visión y perspectivas de sus editores. Se evalúa que la iniciativa es pertinente y contribuye al desarrollo de la Amazonia; sin embargo, aún se resiente de la ausencia de mayor participación en la producción científica de autores residentes en los estados de la región norte, así como del bajo nivel de calidad de los trabajos presentados. Se concluye que el esfuerzo de publicación para mantener ese periódico cuatrimestral retrata la satisfacción de los editores en contribuir con la diseminación del conocimiento y propiciar a los investigadores y académicos de la Amazonia un camino potencial para compartir con la comunidad científica sus reflexiones y resultados de investigación acerca de la región. Palabras clave: Periódico. Progreso académico-científico. Amazonia. 


\section{INTRODUÇÃO}

Os periódicos com origem em universidades públicas, principalmente considerando os que se destinam à produção intelectual para o avanço das ciências, enfrentam um trade-off permanente. Como manter a revista? Como financiar os registros nas certificadoras e custear sua impressão, quando existe uma versão impressa? Custear com a inserção de anúncios em suas páginas? Como fazer isso se as entradas de recursos nas instituições federais de Ensino Superior (Ifes) devem ser creditadas no "Fundo Único do Tesouro". Cobrar pelas publicações dos artigos? Falar nisso dentro das Ifes soa como uma ação mercantilista que conduzirá diretamente à "Santa Inquisição" - e, se o proponente tiver sorte, ao cadafalso.

Considerando todas essas probabilidades, a tendência tem sido a modalidade eletrônica, onde ocorre redução dos cursos de publicação - porém, estes não são eliminados. Por exemplo, há custos de certificação, suporte técnico, design gráfico, Digital Object Identifier (DOI), gestão editorial, entre outros. Então, para manter uma revista ativa em uma universidade federal, o editor sempre é o provedor e exerce seu ofício com o espírito encarnado do mecenas. O editor é quem financia as edições e tem como retorno - quando este ocorre - o reconhecimento e o prestígio no meio acadêmico e científico nacional, contando com o apoio de voluntários, seus abnegados orientandos e ex-orientandos, que comungam a ideia de que a disseminação do conhecimento é tão relevante quanto os achados das pesquisas.

Outro modo de encarar a existência de uma revista em uma universidade pública é a crença de que existindo um periódico enquadrado em uma categoria Qualis da Coordenação de Aperfeiçoamento de Pessoal de Nível Superior (Capes). Esse registro possibilita aos professores e alunos dos cursos de graduação e de pós-graduação de Ifes um canal para divulgar suas produções cientificas e, também, servir como alavanca aos cursos stricto sensu existentes.

Entretanto, às vezes, correntes de dominação existentes na Ifes veem uma iniciativa como essa como ameaça ao seu "curral" de influência e boicotam de todos os modos sua existência ou, ainda, se isso não ocorrer, ignoram, deixando-a sem apoio ao seu funcionamento na instituição. Essas e outras questões não menos importantes minam as iniciativas que conduzem, via de regra, ao encerramento e fechamento das revistas. Algumas vezes, esse caminho ao gólgota se mostra longo e doloroso.

Considerando que a Revista de Administração e Negócios na Amazônia (Rara) é um periódico concebido para publicar preferencialmente temas relacionados ao desenvolvimento sustentável, tendo a Amazônia como foco de pesquisa, a luta para manter uma publicação desse tipo é ainda mais árdua. $O$ universo de pesquisa é imensurável, considerando a Amazônia como lócus de estudo e as possibilidades são tão grandes quanto as impossibilidades de chegar a uma unidade de análise para iniciar uma investigação. Aqui, estamos considerando as Ciências Sociais aplicadas como área de estudo.

Estão associadas a isso as dificuldades mencionadas, a falta de experiência de um corpo de pesquisadores locais no sentido de captar recursos para a realização de pesquisas de campo - tendo em vista as distâncias espaciais que chegam a rivalizar com as expedições dos pioneiros ingleses ao Lago Vitória, na África, ou mesmo as tentativas de chegar ao Polo Norte ou à Antártida. Como experiências em deslocamento com estudantes de mestrado e mesmo de graduação no estado de Rondônia, pode-se citar, por exemplo, o espaço físico do território de Porto Velho. A área desse município faz limite com o estado do Acre, a oeste e, na outra ponta, ao leste, limita-se com o estado do Mato Grosso. São distâncias gigantescas que exigem esforço e muitos recursos para a realização de estudos de campo e a compilação de informações acerca de certa realidade. Para ter uma noção da magnitude, pode-se comparar, como exemplo, Portugal na Europa, onde o território português mede $500 \mathrm{~km}$ de comprimento por $250 \mathrm{~km}$ de largura, todo servido por estradas e meios de comunicação. Certos trechos de viagem na Amazônia custam mais do que um trecho de viagem entre o Brasil e Miami (Flórida, Estados Unidos da América - EUA) ou até entre o Brasil e a cidade do Porto (Portugal). Como se pode produzir conhecimento em um ambiente como esse com poucos recursos?

Esse foi o grande desafio da Rara. Ela foi criada por pesquisadores do Centro de Estudo Interdisciplinar em Desenvolvimento Sustentável da Amazônia (Cedsa), cujo grupo de pesquisa é vinculado ao Programa de Pós-Graduação em Administração da Universidade Federal de Rondônia (PPGA/Unir).

Este artigo relata a experiência dos editores de uma revista cujo objetivo é publicar sobre Administração e Negócios na Amazônia, considerando a contribuição desse periódico para o avanço científico acadêmico na Amazônia focando o desenvolvimento sustentável. 


\section{REFERENCIAL TEÓRICO}

As abordagens paradigmáticas no campo da Administração devem provocar os pesquisadores de modo a proporcionar reflexão sobre as proposições, estratégias, valores e práticas da comunidade científica. Os periódicos científicos acadêmicos são espaços que favorecem a compreensão e apropriação da produção do conhecimento científico, possibilitando que os pesquisadores ampliem seus escopos, uma vez que passam a ter outras escolhas, além das epistemológicas, como as questões regionais, políticas e sociais.

A construção do conhecimento pode ser compreendida como o trabalho com saberes universalmente aceitos em determinado tempo histórico ou decorrente do processo de aprendizagem do sujeito (WERNECK, 2003). Estes saberes advêm: empiricamente, aprendendo a fazer; por experiência; por um comportamento de fé, superstições; dentre outros. Marconi e Lakatos (2003) denominam estes saberes de conhecimento como: popular; filosófico; religioso; científico. Para Werneck (2003), a construção do conhecimento não é totalmente livre ou aleatória, mas ligada a uma unidade de pensamento, a uma concordância, a um consenso universal. A ciência gera uma forma de conhecimento: o conhecimento científico (BAZZO, VON LINSINGEN e PEREIRA, 2003; MARTINS, 2006).

O conhecimento científico difere dos demais tipos de conhecimento por apresentar metodologia e visão crítica (TRUJILLO, 1974). Também é resultante de atividades de pesquisadores, devendo obedecer a padrões previamente estabelecidos. Qualquer pesquisa tem por objetivo fundamental "descobrir respostas para problemas mediante o emprego de procedimentos científicos" (GIL, 1999, p. 42), segundo os quais "pesquisar não é apenas procurar a verdade; é encontrar respostas para questões propostas, utilizando métodos científicos" (LAKATOS e MARCONI, 1996, p. 15). A pesquisa é uma "atividade pela qual descobrimos a realidade" (DEMO, 1987, p. 23) e como um meio para adquirir conhecimento sobre determinada realidade. É importante que esse conhecimento seja disseminado para a acumulação e transferência de conhecimento e avanço científico.

Por outro lado, o conhecimento científico pode ser tácito e/ou explícito. O explícito é aquele que pode ser formalizado em palavras, números e sons, passível de codificação, e pode ser transmitido aos indivíduos, formal e sistematicamente. Compreende todas as formas de comunicação científica, avaliadas ou não. Por sua vez, o conhecimento científico tácito pode ser compreendido como o conhecimento ou a habilidade que pode ser passada entre pesquisadores por contatos pessoais, mas não pode ser exposto ou passado em fórmulas, descrições ou instruções para ação (COLLINS, 2001).

Assim, o reconhecimento do valor de uma pesquisa científica depende de sua divulgação entre os pares e demais grupos da comunidade científica interessados em seus resultados práticos (MARTINS, 2003; BUENO, 2010). Percebe-se que a comunicação é essencial para a natureza e a prática da ciência (RUSSELL, 2001). Para Garvey (1979), a comunicação científica pode ser compreendida como o estudo das atividades que ocorrem entre os produtores da informação científica, que vai desde o início da pesquisa até a publicação de seus resultados, sua aceitação e integração a um corpo de conhecimento científico. $O$ que, para Russell (2001), demonstra que a comunicação está presente em todas as etapas do processo de pesquisa e exerce importante função na criação, no uso e no compartilhamento de conhecimento científico.

\section{ASPECTOS METODOLÓGICOS}

Este estudo teve abordagem qualitativa, de natureza exploratória, com objetivo de descrever a trajetória da Rara. Os procedimentos foram orientados para relatar a experiência de seus editores. Utilizou-se como base de dados o site da própria revista. Os dados transformados em informações serviram de base para analisar a contribuição do periódico para o avanço científico acadêmico na Amazônia. O período de análise compreende as edições impressas e as eletrônicas de 2009 a 2017. Descrevemos as estratégias de criação, editoração, penetração no âmbito acadêmico e avanço da Rara, pontuando a visão e as perspectivas de seus editores.

\section{RESULTADOS E DISCUSSÃO}

Neste ponto, concentramos a descrição dos resultados e das reflexões em função do aporte teórico proposto, com o intuito de contribuir com a discussão sobre a geração do conhecimento a partir da comunicação dos resultados de pesquisa e do esforço de manter um periódico na diversidade institucional. 


\section{Visão dos editores da Revista de Administração e Negócios na Amazônia: proposta, capacitação e criação}

A proposta de criação da Rara ocorreu no final de 2008, quando pesquisadores e discentes do PPGA/Unir e alunos de iniciação científica, membros do grupo de pesquisa do Cedsa, estavam reunidos para elaborar o planejamento de 2009 . Por ocasião da análise da matriz SWOT (acrônimo, em inglês, de forças [strengths], fraquezas [weaknesses], oportunidades [opportunities] e ameaças [threats]) surgiu fortemente o ressentimento de ter pouco acesso aos resultados das pesquisas realizadas na Amazônia por pesquisadores locais e, ainda, da inexistência de um periódico que proporcionasse a divulgação e disseminação dos achados e reflexões sobre Administração e Negócios na Amazônia. Nesse momento, iniciou-se a criação do periódico com a chancela do Cedsa. As estratégias e os planos foram traçados e o nome foi definido; além disso, ocorreu a devida distribuição de tarefas e responsabilidades. No entanto, houve a ponderação decorrente de outras iniciativas frustradas de criação de periódicos no percurso de aprovação dos conselhos instalados na estrutura da Unir, o que foi logo rechaçado pelo nível de entusiasmo e motivação que sustentava a visão de ter na Amazônia um periódico que pudesse contribuir com o avanço científico acadêmico.

Vale destacar a convicção daquele pequeno grupo de que teria todas as condições para implementar e manter a Rara, a qual já estava instalada no imaginário do grupo de pesquisa Cedsa, com o propósito de contribuir para a divulgação do conhecimento científico na área de Administração e Negócios na Amazônia. Assim como em áreas correlatas, com acesso gratuito. Entretanto, tinha-se a clareza de que muitas etapas estavam por vir. Naquele momento surgiu a reflexão que a melhor estratégia seria uma revista eletrônica e, também, definiu-se o corpo editorial, a plataforma digital, o gerenciamento, o regimento e os avaliadores. Após muitas questões levantadas, a primeira decisão foi providenciar a capacitação da equipe, definir o logotipo, elaborar o regimento e iniciar a cruzada burocrática para institucionalizar o periódico do Cedsa na Unir.

A capacitação inicial se deu por autoconhecimento, pesquisa em outras plataformas, editoriais, produção científica sobre a criação e manutenção de periódicos e normalização da Capes. Essa base possibilitou o entendimento sobre a gestão de um periódico e, também, sua complexidade, o esforço e empenho para manter a Rara. Para utilizar o processo de gerenciamento editorial, automatizado por meio da plataforma digital, era preciso fazer a capacitação no Serviço de Eletrônico de Editoração de Revistas (SEER). Decididos os papéis da equipe, o assistente do editor também ficaria responsável pelo suporte técnico. Um aluno de mestrado que é analista de informática, voluntário, foi convidado a fazer a capacitação sobre o SEER, no Rio de Janeiro, no Instituto Brasileiro de Informação em Ciência e Tecnologia (IBICT). Como não havia recursos da instituição, tratava-se de uma atividade não institucionalizada. Diante disso, a equipe bancou o deslocamento do assistente do editor para fazer o curso durante uma semana, o que, sem dúvida, viabilizou a implementação do periódico. Deve-se registrar que a Rara continua contando com esse competente assistente.

A Rara foi criada utilizando o gerenciamento editorial automatizado, de modo a garantir transparência e universalidade de acesso a leitores e autores, o que enriquece o intercâmbio entre instituições nacionais e internacionais. A Figura 1 apresenta a capa no site da revista.

Figura 1

Capa no site da Revista de Administração e Negócios na Amazônia

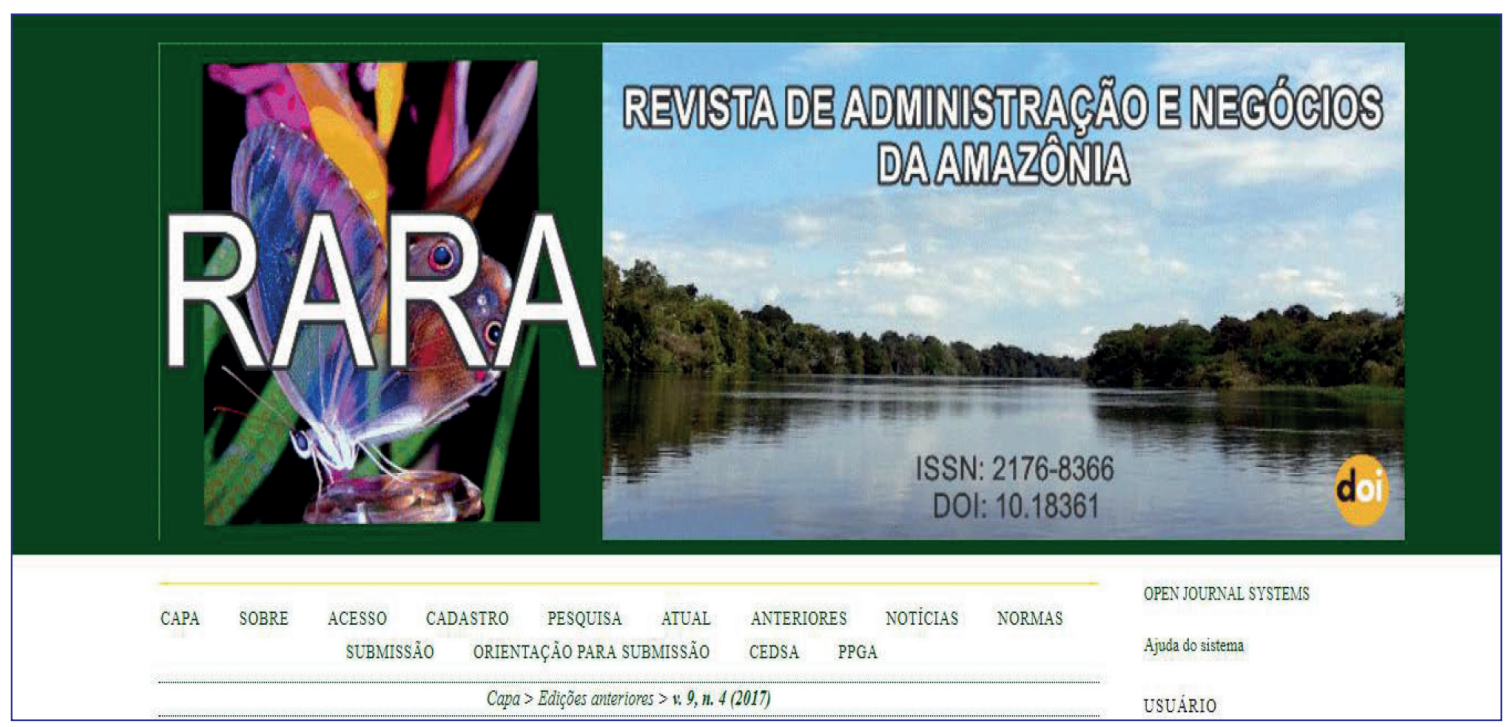

Fonte: Rara (2018). 
O periódico on-line foi registrado sob o ISSN 2176-8366, com publicação quadrimestral. A Rara vem sendo publicada ininterruptamente desde o segundo quadrimestre de 2009, como versão on-line, tendo posteriormente providenciado o registro no DOI, que consiste em um diferencial entre os periódicos. A Figura 2 apresenta a capa da primeira edição da Rara.

Figura 2

Capa da primeira edição da Revista de Administração e Negócios na Amazônia

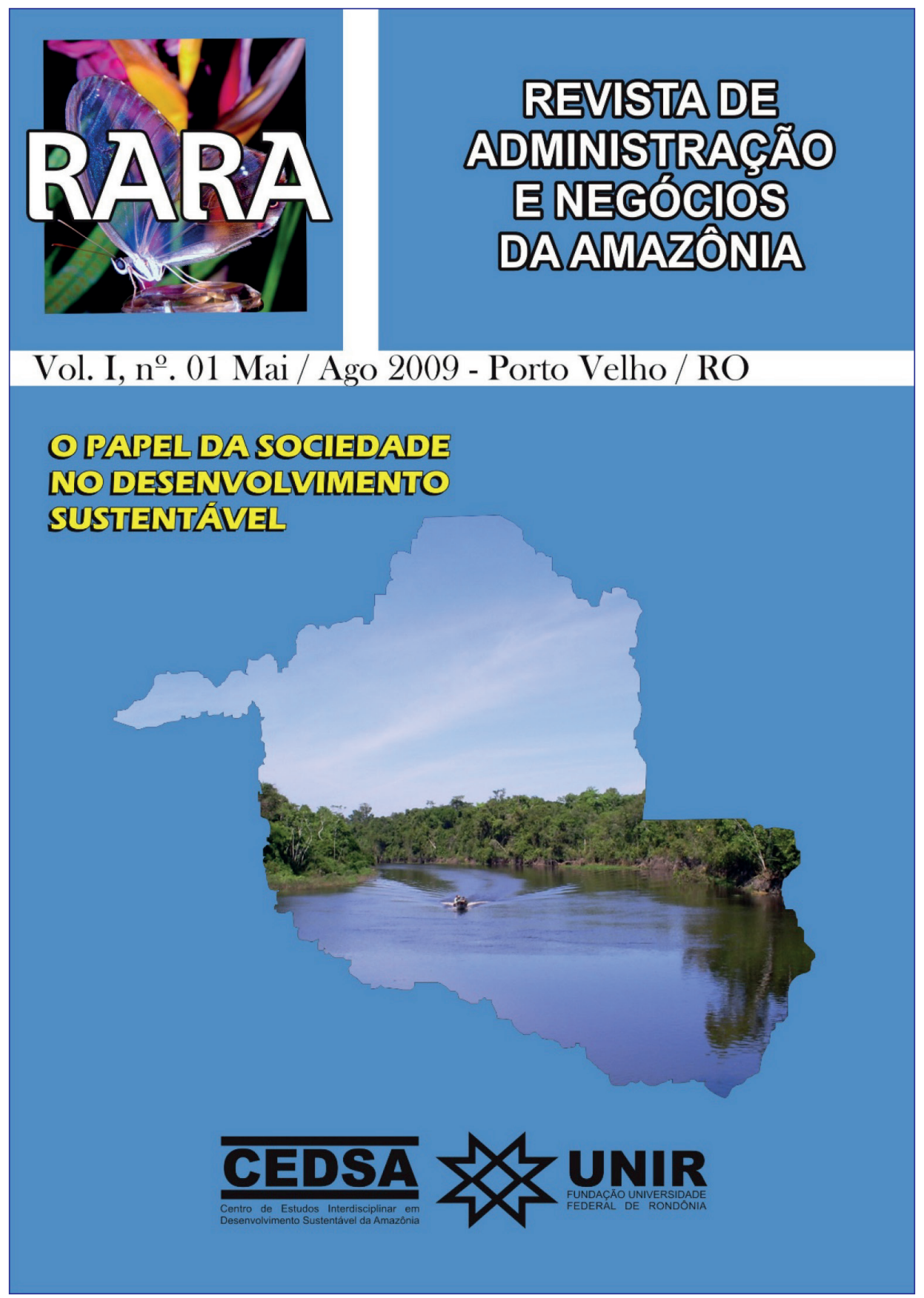

Fonte: Rara (2018).

A Rara foi a primeira revista eletrônica da área na Amazônia e adota as melhores práticas editoriais, seguindo as recomendações e normas do Qualis da Capes, publicando artigos avaliados no sistema de avaliação duplo-cega. 
No segundo semestre de 2010, a Rara foi lançada em versão impressa (ISSN 2178-9320), com edição anual, a qual tinha a classificação B3, mas foi suprimida na avaliação de periódicos do Qualis da Capes de 2015, decisão que levou ao encerramento dessa publicação.

\section{Perspectivas dos Editores da Revista de Administração e Negócios na Amazônia}

Manter a publicação impressa por 5 anos requereu um grande esforço da equipe editorial, no entanto, a busca de recursos por meio de doações voluntários representava o maior desafio. Mantinha-se em função do sentido de que a revista impressa representava para a região, pois em muitos lugares da Amazônia não tem energia, muito menos internet para acesso à versão eletrônica da Rara. A Figura 3 apresenta a capa da primeira edição da versão impressa da revista.

Figura 3

Capa da primeira edição da versão impressa da Revista de Administração e Negócios na Amazônia

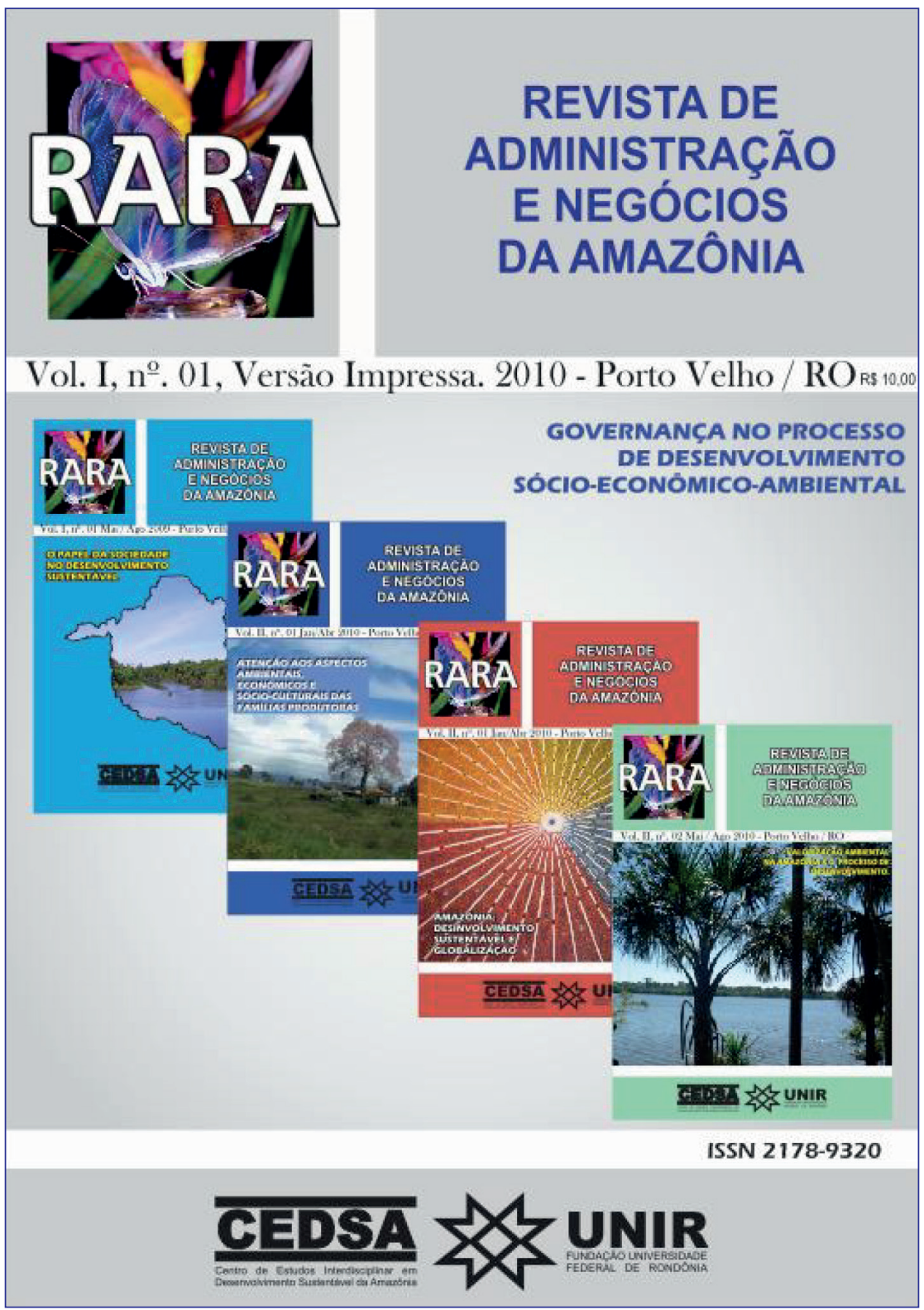

Fonte: Rara (2010). 
Portanto, a versão impressa se justificava na Amazônia por facilitar a distribuição e fazer chegar a comunicação das pesquisas em locais, comunidades e instituições de ensino públicas e privadas que não tinham acesso à internet. Ao falar em contribuir com o avanço científico acadêmico na Amazônia, antes de qualquer iniciativa, deve-se pensar na estratégia do acesso, nas condições e na logística diante das deficiências do aparelhamento público nessa região. Aos editores, que dedicavam mais de 4 meses de seu tempo na produção da versão impressa, restou o desalento. O mesmo valeu para os pesquisadores encarregados da avaliação do periódico, que deixaram de entender que a estratégia da Rara era atípica (um exemplar anual), mas necessária, voltada a atender as longínquas localidades amazônicas. A Figura 4 apresenta as capas das edições anuais impressas da Rara, de 2011 a 2014.

\section{Figura 4}

Capas das edições anuais impressas da Revista de Administração e Negócios na Amazônia (2011-2014)

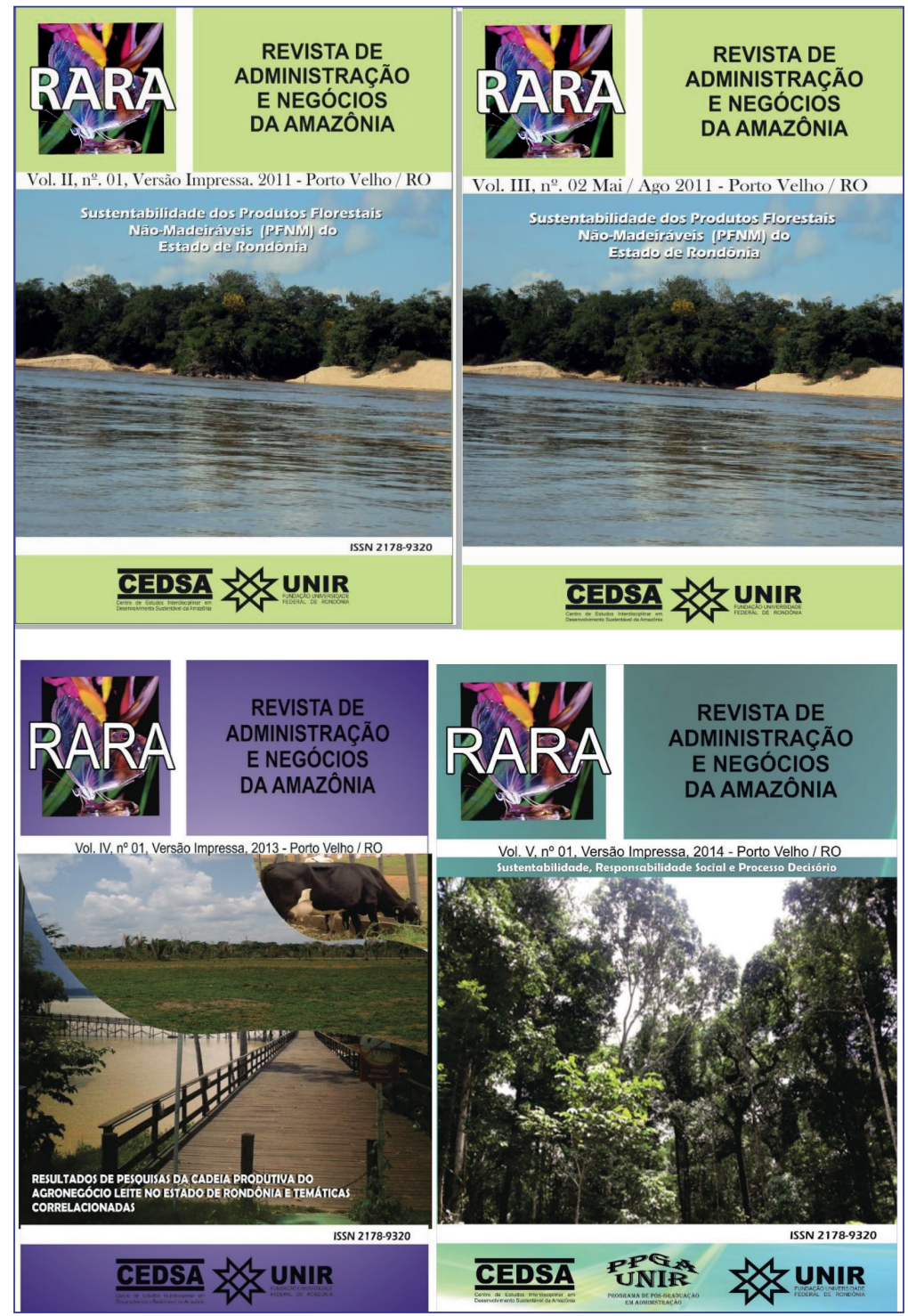

Fonte: Rara (2011, 2012, 2013, 2014).

Destacam-se nessas edições as suas temáticas.

- 2011: Sustentabilidade dos Produtos Florestais Não-Madeiráveis (PFNM) no Estado de Rondônia - edição que reuniu 10 artigos com os resultados de uma pesquisa financiada pelo Conselho Nacional de Desenvolvimento Científico e Tecnológico (CNPq) na modalidade "casadinho"; 
- 2012: Pesquisa Interinstitucional em Administração a Integração da Amazônia aos Pampas - edição que reuniu 10 artigos de alunos de doutorado da Universidade Federal do Rio Grande do Sul (UFRGS) com seus orientadores, parte de um projeto de doutorado interinstitucional financiado pela Superintendência da Zona Franca de Manaus (Suframa). Registra-se que embora tais resultados sejam decorrentes de projetos, eles não dispunham de recursos para impressão de periódicos;

- 2013: Produtos, Serviços e Preservação Ambiental; e

- 2014: Sustentabilidade, Responsabilidade Social e Processo Decisório.

As duas últimas edições reuniram os melhores artigos submetidos no sistema eletrônico, que contavam com a disposição de seus autores em contribuir com os custos de impressão. Vale destacar que todas essas edições foram distribuídas a instituições de Ensino Fundamental, Ensino Médio e Ensino Superior da Amazônia e associações e comunidades tradicionais, que ainda hoje perguntam quando serão enviadas novas edições, recebendo a explicação de que a falta de recursos para a impressão impossibilitou que a versão impressa continuasse.

Essa é a breve história de um periódico que deixou de existir e contribuiu com o já limitado avanço da ciência na Amazônia.

A versão on-line, que vem sendo publicada quadrimestral e sistematicamente desde 2009, tem enfrentado toda forma de dificuldades, no entanto, estas são superadas com a motivação de seus editores e da equipe colaboradora - voluntária, mas incansável para que a próxima edição seja publicada dentro do prazo.

\section{Figura 5}

Capas das edições dos 5 primeiros anos da versão eletrônica da Revista de Administração e Negócios na Amazônia

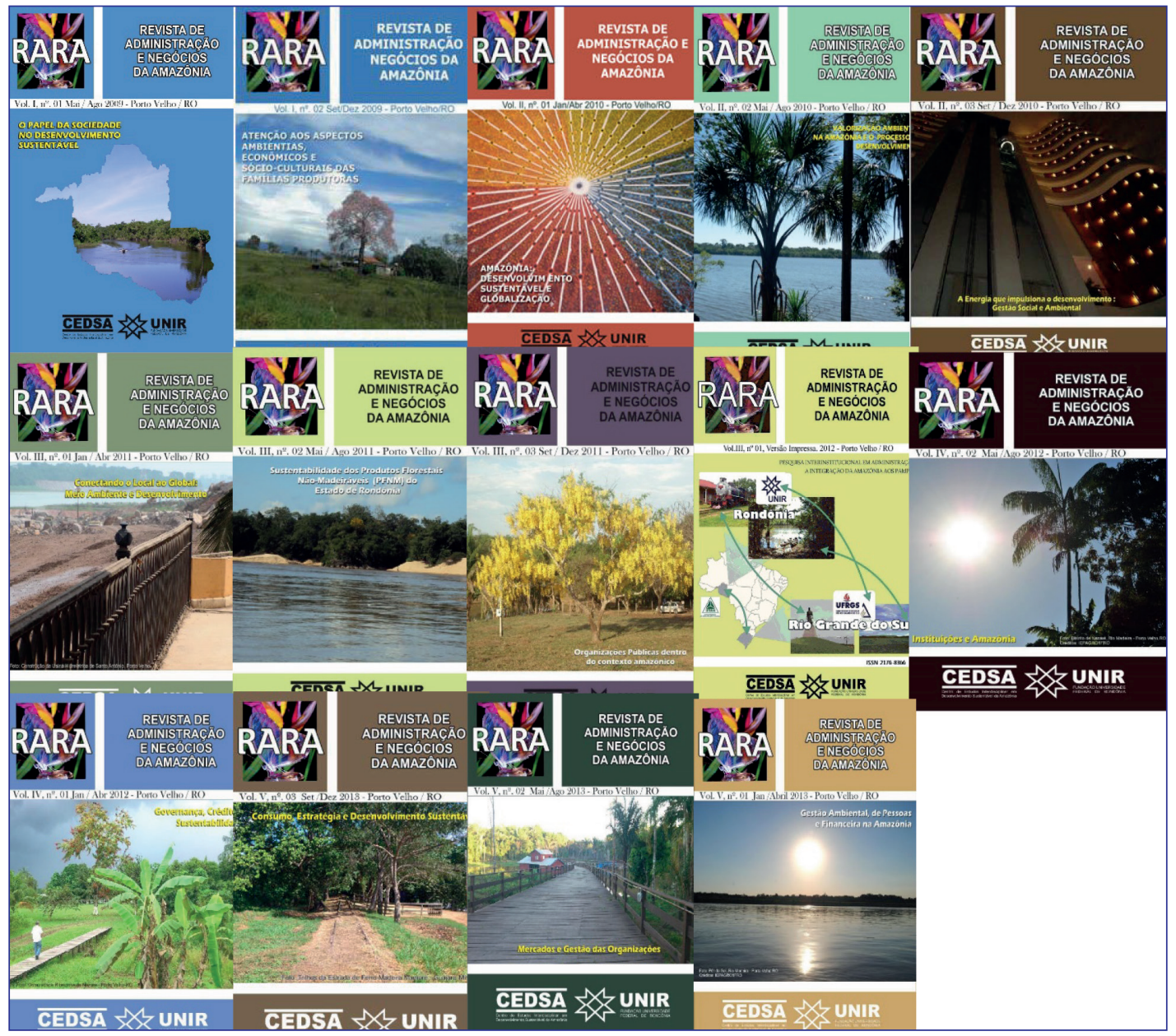

Fonte: Rara (2018). 
Observa-se que as maiores dificuldades encontradas para produzir as edições da Rara consiste em manter suas premissas de divulgação das pesquisas na Amazônia, em função do número insuficiente de submissões de pesquisadores da região. O cuidado com a endogenia na revista leva os editores a aceitar submissões de outras regiões do país, visando a sempre contribuir com a comunicação científica.

\section{Figura 6}

\section{Capas das edições dos 5 últimos anos da versão eletrônica da Revista de Administração e Negócios na Amazônia}

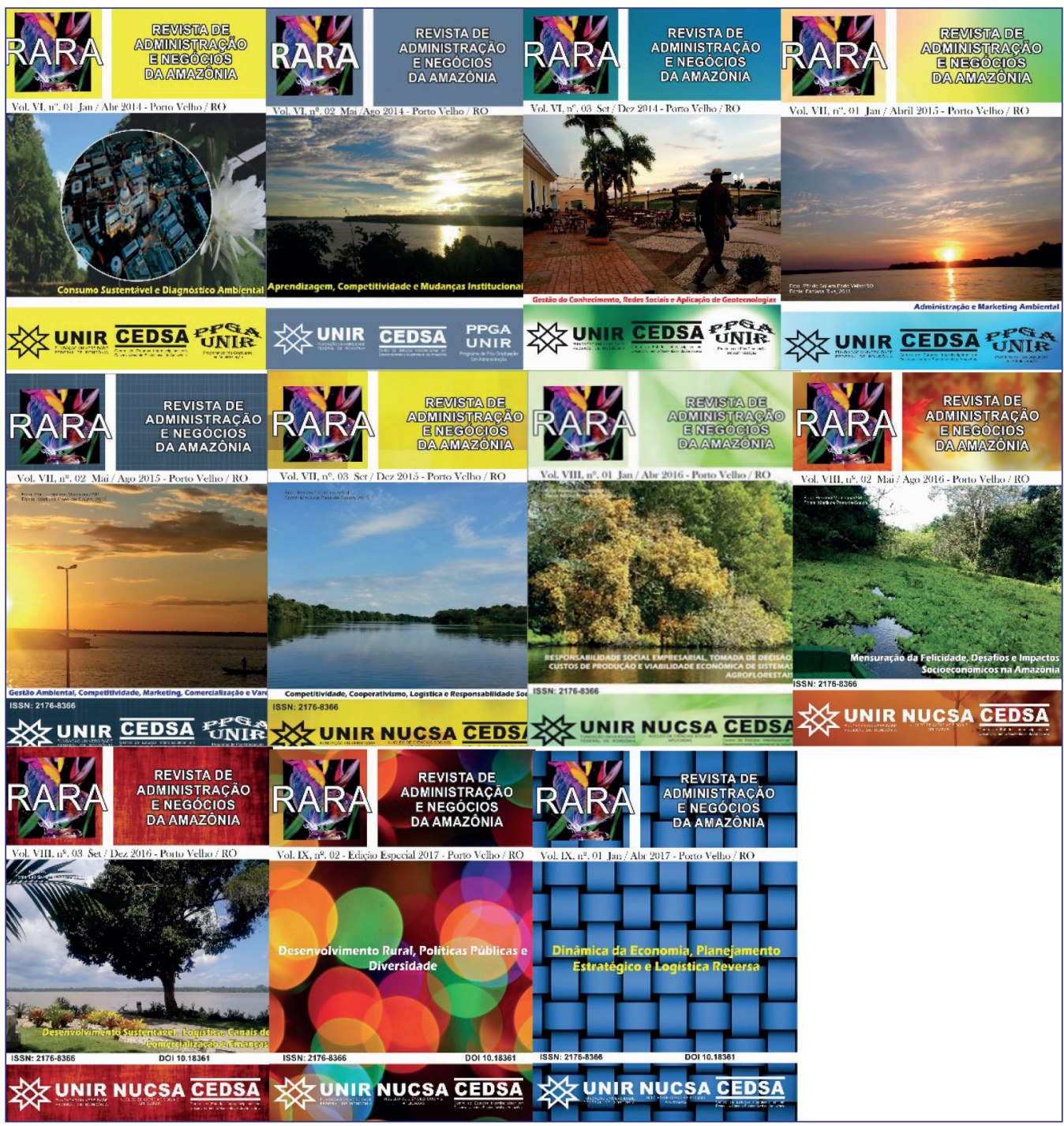

Fonte: Rara (2018).

Destaca-se, ainda, a importância dos avaliadores, aos quais se agradece imensamente, porém, com pouca representação de avaliadores da região, o que parece refletir na pequena incidência de submissões.

\section{CONSIDERAÇÕES FINAIS}

Diante dos fatos apresentados, acredita-se que maior contribuição para o avanço científico acadêmico na Amazônia prescinde de comunicação dos resultados das pesquisas realizadas, que pode ser feita por meio de periódico institucionalizado, mas que 
deve ter o reconhecimento e o suporte das instituições. Como se sabe, os editores não publicam na revista que editam, eles trabalham e mantêm o periódico como instrumento de disseminação do conhecimento de outros pesquisadores, visando ao desenvolvimento da ciência e da região.

Avaliamos que as ações de criar e manter a Rara foram pertinentes e contribuíram para o desenvolvimento da Amazônia. No entanto, ainda se ressente de maior participação na produção científica de autores residentes nos estados da região Norte do Brasil, bem como de maior qualidade nos trabalhos submetidos.

Concluímos que os esforços para manter um periódico quadrimestral retratam a satisfação dos editores em contribuir com a disseminação do conhecimento e proporcionar aos pesquisadores e acadêmicos da Amazônica um veículo para compartilhar suas reflexões e seus resultados de pesquisa sobre a região com toda a comunidade científica. Entendemos que este artigo abre espaço para outras incursões de pesquisa sobre a especificidade das publicações, considerando sua natureza, suas potencialidades, seu rigor e seu impacto científico e social. 


\section{REFERÊNCIAS}

BAZZO, W. A.; VON LINSINGEN, I.; PEREIRA, L. T. V. O que é ciência? In: BAZZO, W. A.; VON LINSINGEN, I.; PEREIRA, L. T. V. Introdução aos estudos CTS (ciência, tecnologia e sociedade). Madrid: OEI, 2003. p. 35-80.

BUENO, W. C. Comunicação científica e divulgação científica: aproximações e rupturas conceituais. Informação \& Informação, v. 15, n. esp., p. 1-12, 2010.

COLLINS, H. M. Tacit knowledge, trust and the $\mathrm{Q}$ of sapphire. Social Studies of Science, n. 31, p. 71-85, 2001.

$\mathrm{DEMO}, \mathrm{P}$. Introdução à metodologia da ciência. 2. ed. São Paulo: Atlas, 1987.

GARVEY, W. D. Communication: the essence of science. Oxford: Pergamon Press, 1979.

GIL, A. C. Como elaborar projetos de pesquisa. São Paulo: Atlas, 1999.

LAKATOS, E. M.; MARCONI, M. A. Pesquisa. In: LAKATOS, E. M.; MARCONI, M. A. Técnica de pesquisa. 3. ed. São Paulo: Atlas, 1996. p. $15-123$.

MARCONI, M. A.; LAKATOS, E. M. Fundamentos de metodologia científica. 5. ed. São Paulo: Atlas, 2003.

MARTINS, R. A. Introdução: a história das ciências e seus usos na educação. In: SILVA, C. C. (Org.). Estudos de história e filosofia das ciências: subsídios para aplicação no ensino. São Paulo: Livraria da Física, 2006. p. 17-30.

MARTINS, R. B. Do papel ao digital: a trajetória de duas revistas científicas brasileiras. 2003. 182 f. Dissertação (Mestrado em Ciência da
Informação) - Programa de Pós-Graduação em Ciência da Informação, Universidade Federal do Rio de Janeiro, Rio de Janeiro, 2003.

REVISTA DE ADMINISTRAÇÃO E NEGÓCIOS DA AMAZÔNIA - RARA. Homepage. 2018. Disponível em: <http://www.periodicos.unir.br/ index.php/rara/index>. Acesso em: 4 jul. 2018.

REVISTA DE ADMINISTRAÇÃO E NEGÓCIOS DA AMAZÔNIA - RARA. Governança no processo de desenvolvimento sócio-econômicoambiental. v. 2, n. 1, 2010. Versão impressa.

REVISTA DE ADMINISTRAÇÃO E NEGÓCIOS DA AMAZÔNIA - RARA. Sustentabilidade dos Produtos Florestais Não-Madeiráveis (PFNM) no Estado de Rondônia. v. 2, n. 1, 2011. Versão impressa.

REVISTA DE ADMINISTRAÇÃO E NEGÓCIOS DA AMAZÔNIA - RARA. Pesquisa Interinstitucional em Administração a Integração da Amazônia aos Pampas. v. 3, n. 1, 2012. Versão impressa.

REVISTA DE ADMINISTRAÇÃO E NEGÓCIOS DA AMAZÔNIA - RARA. Produtos, Serviços e Preservação Ambiental. v. 4, n. 1, 2013. Versão impressa.

REVISTA DE ADMINISTRAÇÃO E NEGÓCIOS DA AMAZÔNIA - RARA. Sustentabilidade, Responsabilidade Social e Processo Decisório. v. 5, n. 1, 2014. Versão impressa.

RUSSELL, J. M. La comunicación científica a comienzos del siglo XXI. Revista Internacional de Ciencias Sociales, n. 168, p. 1-15, 2001.

TRUJILLO, F. A. Metodologia da ciência. 3. ed. Rio de Janeiro: Kennedy, 1974.

WERNECK, V. R. Cultura e valor. Rio de Janeiro: Forense Universitária, 2003.

Theophilo Alves de Souza Filho

Doutor em Ciências Socioambiental pela Universidade Federal do Pará (UFPA); Professor Titular no Departamento Acadêmico de Administração e no Programa de Pós-Graduação em Administração na Universidade Federal de Rondônia (UNIR), Porto Velho - RO, Brasil. E-mail: theophilo@unir.br

Mariluce Paes de Souza

Doutora em Ciências Socioambiental pela Universidade Federal do Pará (UFPA); Professora Associada no Departamento Acadêmico de Administração e no Programa de Pós-Graduação em Administração na Universidade Federal de Rondônia (UNIR), Porto Velho - RO, Brasil. E-mail: mariluce@unir.br

Dércio Bernardes de Souza

Doutor em Agronegócios pelo Centro de Estudos e Pesquisas em Agronegócios na Universidade Federal do Rio Grande do Sul (CEPAN/UFRGS). Professor Adjunto no Departamento Acadêmico de Administração na Universidade Federal de Rondônia (UNIR), Porto Velho - RO, Brasil. E-mail: dercio@unir.br 